\title{
أثر أنموذج بارمان في تنمية التفكيرعالي الرتبة لدى طلاب الصف الخامس الاعدادي في مادة التربية الاسلامية في دولة العراق
}

\author{
أ.د. ر رائد ادريس محمود \\ كلية التربية للبنات- جامعة تكريت- العراق \\ م. إحسان نظير حسين \\ كلية التربية للعلوم الانسانية- جامعة تكربت- العراق \\ ehsannadher@tu.edu.iq
}

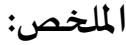

يههدف البحث الحالي إلى التعرف على "أثر أنموذج بارمان في التفكير عالي الرتبة لدى طلاب الصف الخامس الإعدادي في مادة التربية

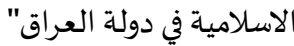

وقد صاغ الباحث الفرضية الصفرية الآتية:

"لا يوجد فرق ذو دلالة احصائية عند مستوى (0.,.) بين متوسط درجات طلاب المجموعة التجريبية الذين يدرسون باستعمال انموذج بارمان

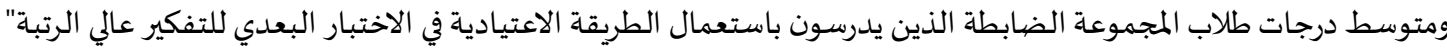

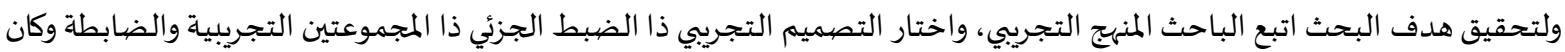

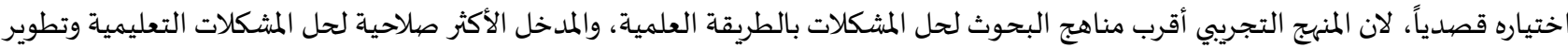

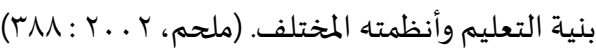

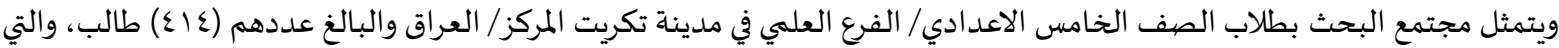

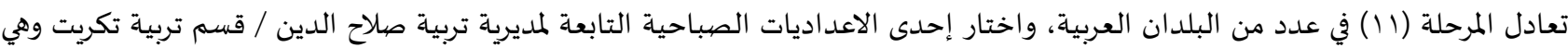
إعدادية ابن المعتم للبنين الواقعة في تكريت ـ حي القادسية.

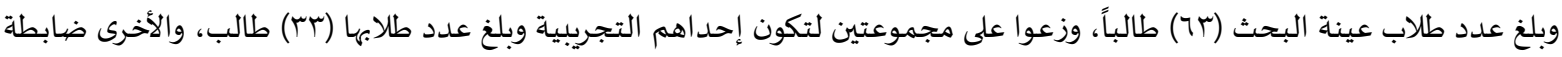

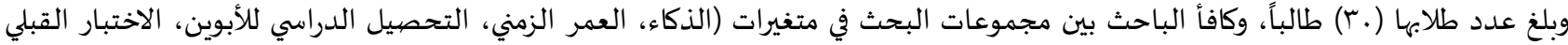

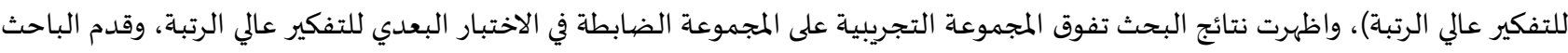
عدداً من الاستنتاجات والتوصيات والمقترحات.

الكلمات المفتاحية: أنموذج بارمان، التفكير عالي الرتبة. @() (1)

المقدمة:

شهد العالم تطورات تكنولوجية وعلمية كبيرة شملت كل جوانب الحياة مما اوجب على دول العالم محاولة مواكبة تلك التطورات

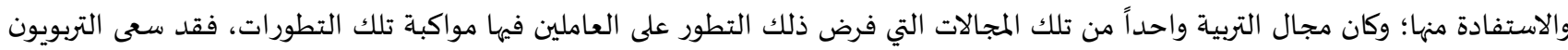

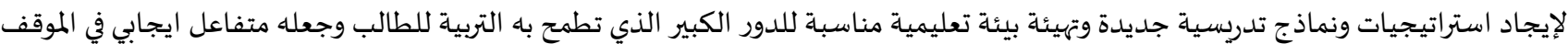

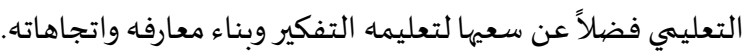

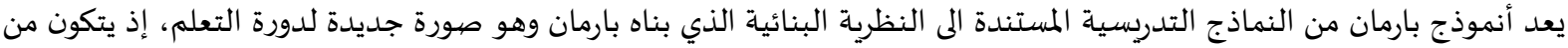

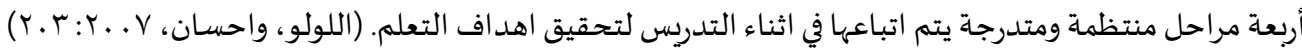


ان المتتبع لواقع تدريس مادة التربية الاسلامية في مدراسنا يلاحظ انه هناك ضعف واضح لدى الطلاب في قدراتهم على استيعاب محتوى تلك

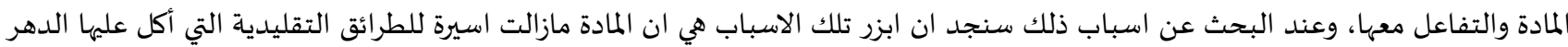
وشرب التي تركز على جانب الحفظ والاستظهار وتغفل جانب الفهم والاستيعاب وتنمية التفكير، فانعكس ذلك سلباً على أداء الطلاب، إذ نجد ان

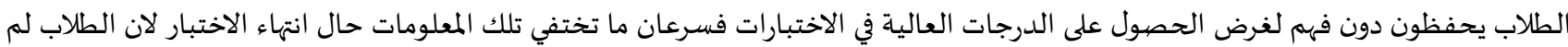
يربطوها ببنيتهم المعرفية وشبكاتهم المفاهيمياة.

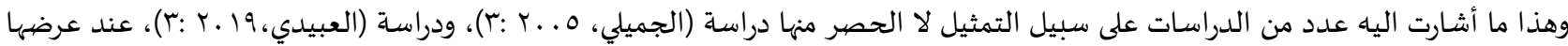

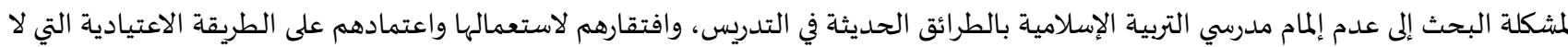

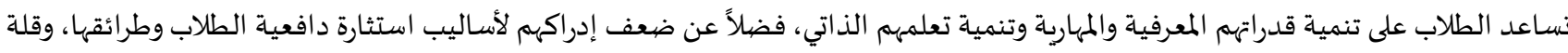

اهتمامهم بتطبيق قواعد تدريس التربية الإسلامية وأسسها. لذا حاول الباحث التقصي عما يسهم في حل بعض المشكلات المتعلقة بتدريس التربية الإسلامية كوناه مهتم بهذا الامر واعتقاده بأن طرائق التدريس

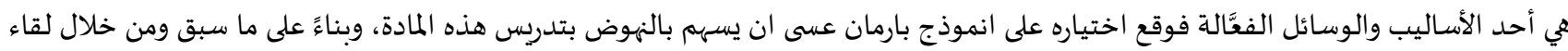

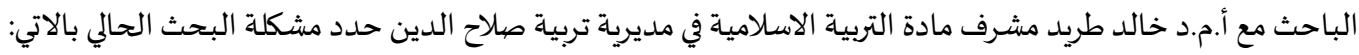
1. إصرار اغلب مدرسي مادة التربية الاسلامية على استعمال الطريقة الاعتيادية. r. عزوف المدرسين او ضعف توجههم او خوفهم من استعمال الطرائق او الاستراتيجيات او النماذج الحديثة.

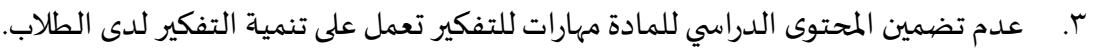

أهمية البحث:

للتربية الإسلامية أثر كبير على النشء وإعداد المواطن الصالح زيادة على تكوين المعتقدات الإيمانية عنده، وتعلمه واجباته نحو ربه والأخرين

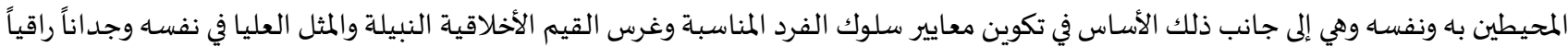
وإرادة قوية متجهه نحو الخير تساعده على تهذيب نفساه ويشمل منهج التربية الإسلامية مواد كسب المهارة وتعلم الصناعات المختلفة والإعداد للحياة

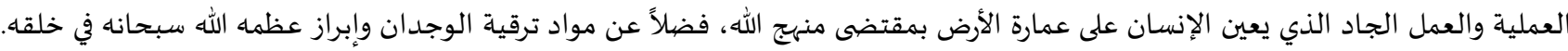

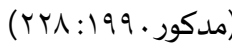

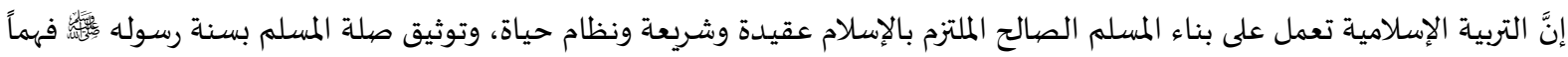

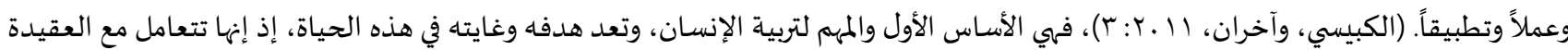
الصحيحة التي ينطلق منها والهها الانسان في كل زمان ومكان متناولاً كل جوانب شخصية الانسان من حيث توجياء سلوكاه وملأ فراغ قلبه والسيطرة على إلى إنها

جوارحه. (عطا، (V)

ويرى الباحث ان التربية الاسلامية هي دستور المسلم وحصنـه المنيع وملاذه الامين ورباطه بربه الكريم؛ لأها مستمدة من القران الكريم الذي

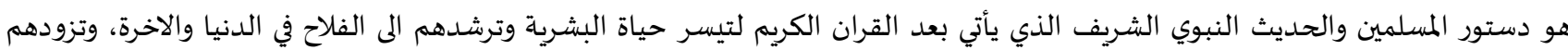

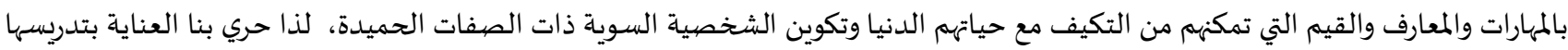
وتذليل كل الصعاب التي تقف عائق أمام تطويرها وازدهاراها. إن تعليم التفكير وتنمية مهاراته يعد هدف اساسي لا يحتمل التأجيل بل ينبغي أن يكون في صدارة الاهداف التربوية لأي مادة دراسية، فهو وثيق الصلة

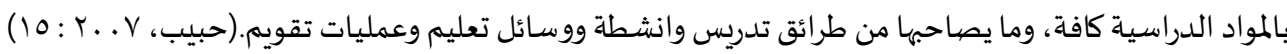

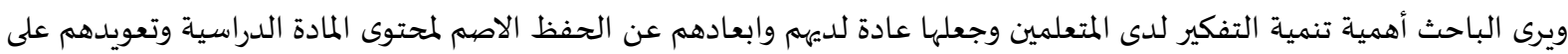
استثمار قدراتهم العقلية وتوظيفها في أثناء تعلمهه ليدركوا حقيقة الأشياء وكي لا يقعوا فريسة للثقافات التي تتعارض مع قيمنا الدينية وعاداتنا الاجتماعياة. ويُعد التفكير عالي الرتبة أحد الابعاد التربوية التي بدا التربويين الاهتمام باه لتحقيق الاهداف التربوية لعملية التعلم والتعليم، ولضمان التطور المعرفي الفعَّال الذي يسمح للأفراد باستخدام اقصى طاقاتهم العقلية لتحقيق النجاح والتكيف السليم في مجال التعلم والحياة العامة. (العتوم

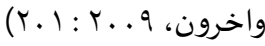


وقد اشـار العديد من الباحثين التربويين إلى أنَّ هذا النوع من التفكير له أهمية كبيرة للنشاط العقليّ ولا ينحصر هذا النشاط على الطلبة الجامعيين وتدريسيهم فحسب بل يتعدى ذلك إلى المستويات والمراحل الأولية، على الرغم من كونه تفكير ينطويّ على تنظيم ذاتيّ لعملية التفكير

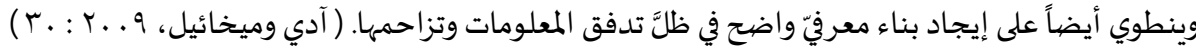

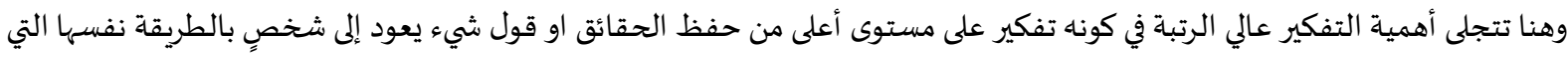
قيل فيها هذا القول، وعندما يحفظ الشخص او يعيد المعلومات من دون الحاجة للتفكير في الامر نحن نسميها الحفظ الاصيه -الحفظ عن ظهي منهر قلب-

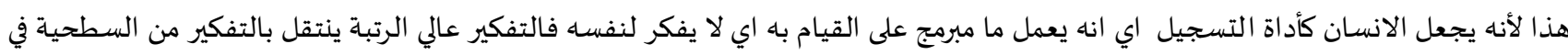

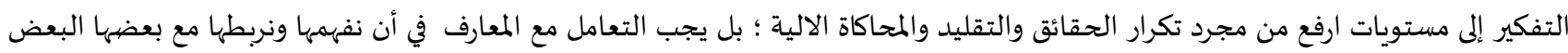

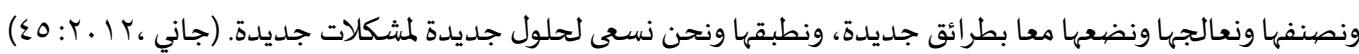

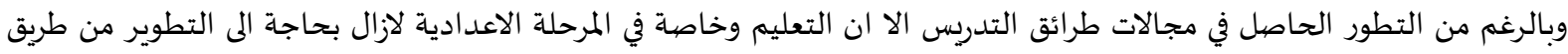

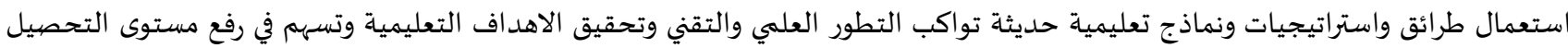

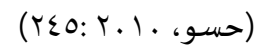

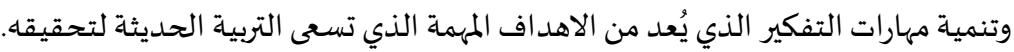

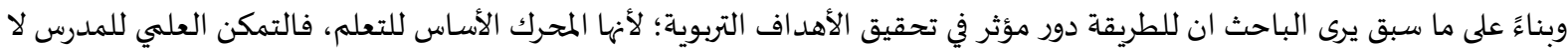
يكفي كي يوصل المحتوى العلمي لطلبته فلابد له من طريقة فضلى تمكناه من إيصال معلوماته لطلبته وتحفزهم للتعلم وتقضي على التهات الرتابة والمللل في داخل غرفة الصف.

وأنبثق أنموذج (بارمان) من الفلسفة البنائية القائمة على تفسير المتعلم للظواهر ومدى استيعابها في ضوء خبرته السابقة، إذ نادت ضرورة

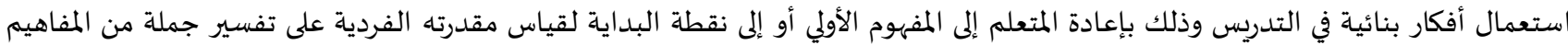

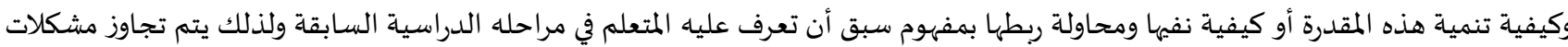

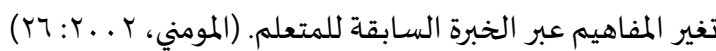

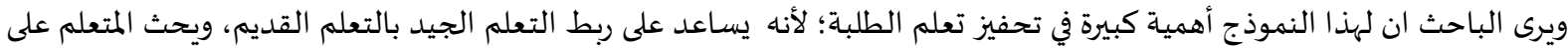
توسيع معلوماته عن طريق تقديم الأمثلة وإعطاء التطبيقات المتنوعة مما يسههم في إثراء عملية تعلم الطلبة وتثبيتها فئها في ذاكرتهه.

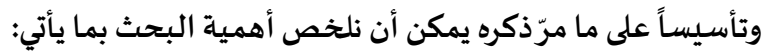

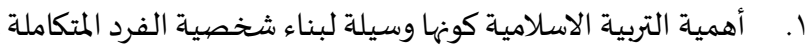
r. أهمية التفكير عالي الرتبة كونه اداة المتعلم لحل مشكلاته وادراك العالم من حولهيه. r. إهمية انموذج بارمان كونه من نماذج التعلم الحديثة التي تعمل على تنمية التفكير.

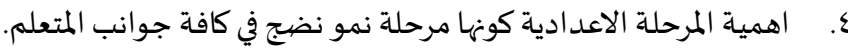

$$
\text { هدف البحث: }
$$

"اثر انموذج بارمان في تنمية التفكير عالي الرتبة لدى طلاب الصف الخامس العلمي في مادة التربية الاسلامية في دولة العراق".

فرضية البحث:

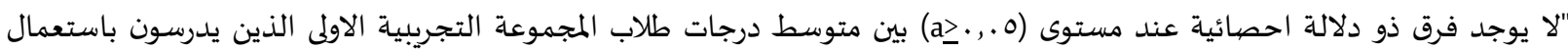
انموذج بارمان ومتوسط درجات طلاب المجموعة الضابطة الذين يدرسون باستعمال الطريقة الاعتيادية في الاختبار البعدي للتفكير عالي

$$
\text { الرتبة" }
$$

$$
\text { حدود البحث: }
$$

يتحدد هذا البحث بـ

ا. الحدود المكانية: طلاب الصف التهذ الخامس العلمي في المدارس الثانوية والاعد ادية في محافظة صلاح الدين/مركز مدينة تكريت.

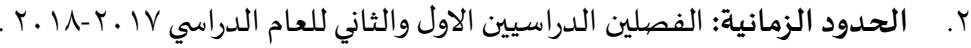

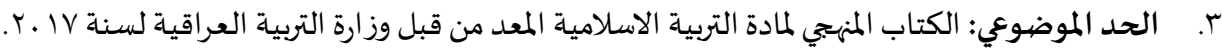

تحديد المصطلحات:

11 
أولاً: أنموذج بارمان: عرفه كل من:

بارمان (Barman) بأنه: هي احدى نماذج التدريس الحديثة التي تؤكد على التفاعل الايجابي بين المعلم والمتعلم وتسير وفقاً لأبربعة مراحل هي:

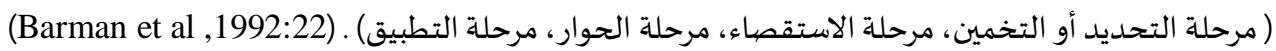

زاير وآخرون بأنه : " أنموذج تعليمي يستند اللى التعلم البنائي، يتكون من أربع مراحل تؤكد المعرفة القبلية للطلبة بصفتها مرحلة تسبق

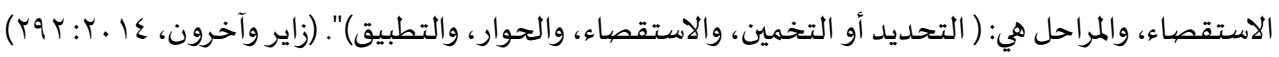

التعريف الإجرائي لنموذج بارمان:

هي خطوات نموذج تدريسية أعتمدها الباحث مع طلاب الصف الخامس الادبي (المجموعة التجريبية) في أثناء تدريسه لموضوعات كتاب التربية الإسلامية على وفق مراحله الاربع [مرحلة التحديد أو التخمين (Assessment Phase)، مرحلة التطبيق (Application Phase)، مرحلة الحوار(Dialogue Phase)، مرحلة الاستقصاء (Investigative Phase) ] لتنمية تفكيرهم عالي الرتبة. ثانياً: التفكير عالي الرتبة: عرفه كل من: ليبمان (Lipman) بأنه: "التفكير الجيد الذي يجمع في ما بين مكونيه التفكير الناقد والتفكير الإبداعي أي أنه مكافئ لاندماج كلا النمطين من التفكير حيث يتضمن التفكير الناقد المحاكمة المنطقية ، في حين يتضمن التفكير الإبداعي المحاكمة العقلية الإبداعية ، فالتفكير الجيد يتكون

من مجموع القدرات الناقدة والإبداعية والتي تساعد الفرد على أن يصحح تفكيره بنفساه ويفكر تفكيراً عقلياً" .(ليبمان ، العتوم وآخرون بأنه: مجموعة من المهارات التي تتضمن ملاحظة وتصنيف وتنظيم المعلومات والقدرة على التساؤل الناقد وحل المشكلات

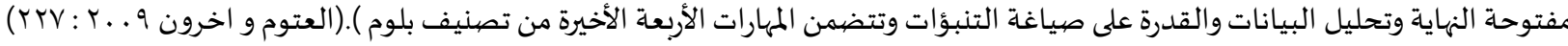
التعريف الإجر ائي للتفكير عالي الرتبة: هو الدرجة الكلية التي يحصل عليها طلاب الصف الخامس العلمي قبل وبعد تدريسهم للنموذج التعليمي (بارمان) على اختبار كاليفورنيا لمهارات التفكير عالي الرتبة بمجالاته الأربعة المعد لأغراض البها لبحث البحث الحالي.

النظربة البنائية:

إن كلمة بنائية مشتقة من البناء أو البنية وتطلق في العربية الى ما يبنى وبنية الشيء هيأته التي بني عليها؛ ومن هذا المفهوم ينطلق البنائيون في رؤيتهم للوجود، إذ يرون أن كل ما في الوجود هو عبارة عن بناء متكامل يشتمل على ابنية جزئية تربط بينها علاقات محددة ولا قيمة للأبنية الجزئية

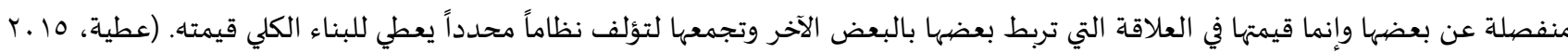

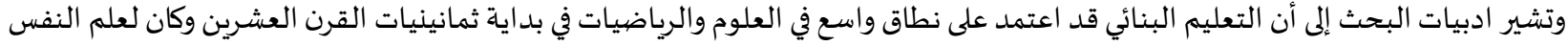

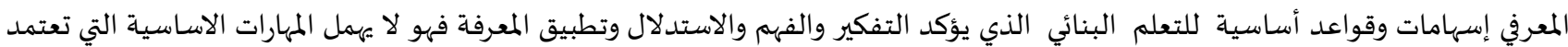
على الفكرة التي ترى الطالب يبني معرفته بنفسـه، فهو ينظر إلى التعلم على أنه نتيجة لبناء عقلي، فالطلاب يتعلمون من طريق تنظيم وموائمة

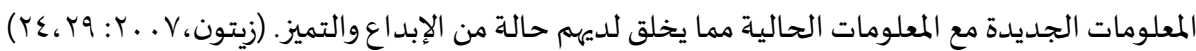
ويتضح للباحث مما سبق أن النظرية البناية عبارة عن مجموعة من أفكار العلماء في كيفية تنظيم المعلومات وبنائها في ذهن المتعلم، إذ يرى هؤلاء

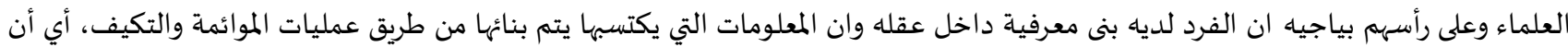
المعلومات التي تلقاها الفرد تتعرض لعمليات عقلية داخلية من أجل تكيفها مع بنية الفرد السابقة.

وقد استندت البنائية مبدئيا إلى أربع نظريات وهي: 1. الظرية بياجياء في التعلم المعرفيّوالنمو المعرفيّ.

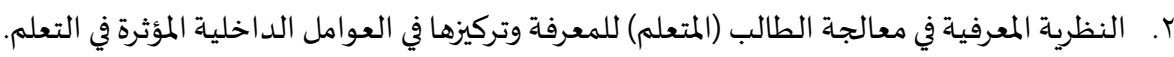

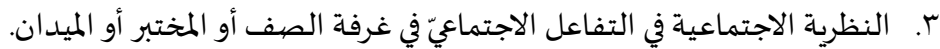

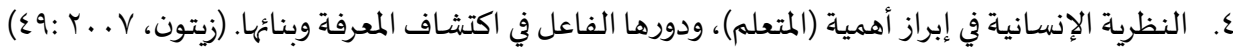

الأسس التي تستند إليها النظرية البنائية :

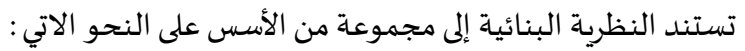

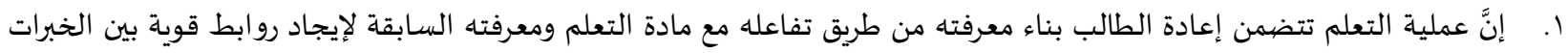
الجديدة والخبرات السابقة .

r. إنَّ التدريس الفعال يعتمد بشكل كبير على مدى تهيئة الفرص الملائمة التي تمكن الطالب من أداء دورهُ الإيجابي في عمليات بناء المعرفة 
ا. التشـيد على الطرائق والأسـاليب التي تزيد من فرص المشـاركة الإيجابية للطلبة ومن تلك الطرائق: هي المناقشة والاستجواب وحل المشكلات

$$
\text { والعصف الذهني. }
$$

ع. للتفاعل المشترك بين الطلبة من جانب، والطلبة والمعلم من جـانب آخر لما له من دور في عملية التعلم.

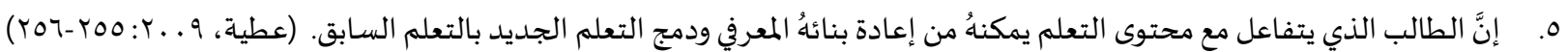

ويتفق الباحث الى ما ذهب اليه (عطية) الى أن النظرية البنائية تستند الى أسس في مقدمتها نشاط المتعلم ودوره الإيجابي في التعلم، وان

$$
\text { التعلم عملية اجتماعية تفاعلية تجري من طريقها بناء المعارف لدى الافراد. }
$$

المبادئ التي نادت بها النظرية البنائية في التعلم:

نادت النظرية البنائية بمجموعاة من المبادئ منها:

ا. . المتعلم لا يتلقى ولا يستقبل المعرفة بشكل سلبي، وانما يتم بنائها من خلال نشاطه ومشـاركته الفاعلة في عمليتي التعليم والتعلم. r. تلعب معلوماته وخبراته السـابقة دوراً اساسياً في بناء التعلم اللاحق حيث تؤثر هذه الخبرة في تعلمه للمعرفة الجديدة وقد تؤثر سلباً ان كانت

غير صحيحة.

ا. يبني المتعلم معنى ما تعلماه بنفساه بناء ذاتياً، حيث يتشكل المعنى داخل بنيتاه المعرفية بناءً على رؤية خاصية باه، فالأفكار ليست ذات معنى

ثابت لدى الافراد.

ع. المعرفة ليست موجودة بشكل مستقل عن المتعلم فهي من ابتكاره وتكمن في عقله ثم انها تصبح اسـاس نظرته الى العالم من حوله.

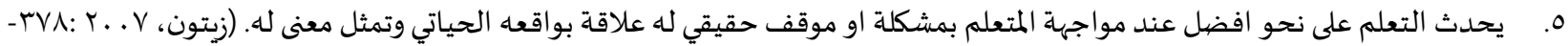

(rVq

يتضح مما سبق أن من أبرز مفاهيم النظرية البنائية هي التركيز على المتعلم الإبداعي والمتفاعل والاجتماعي، مما يمكن المتعلم من بناء معارفه بنفسـا

بحيث تكون ذات معنى لدياه.

وقدمت النظرية البنائية عدداً من النماذج التدردسية ومن هذه النماذج ما تناوله البحث الحالي وهو انموذج بارمان التدردي.

أنموذج بارمان (Barman)

من التطورات التي تميزت بطابع الحداثة التي حدثت في الدراسات والبحث ذات العلاقة بالنمات النمو العقلي للمتعلم خاصة من المنظور المعرفي

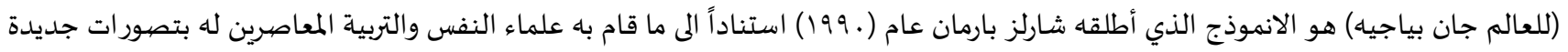

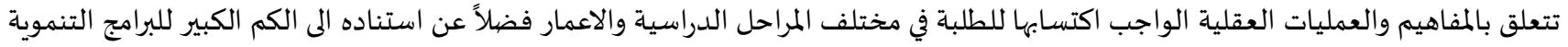

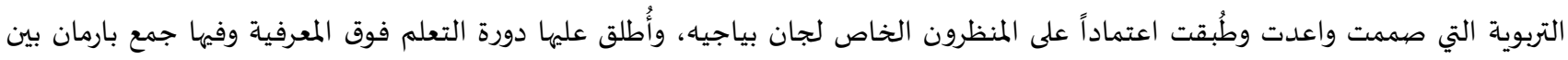

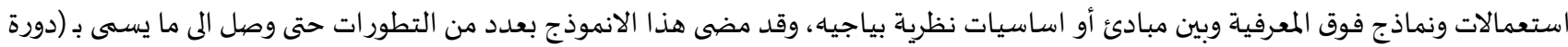

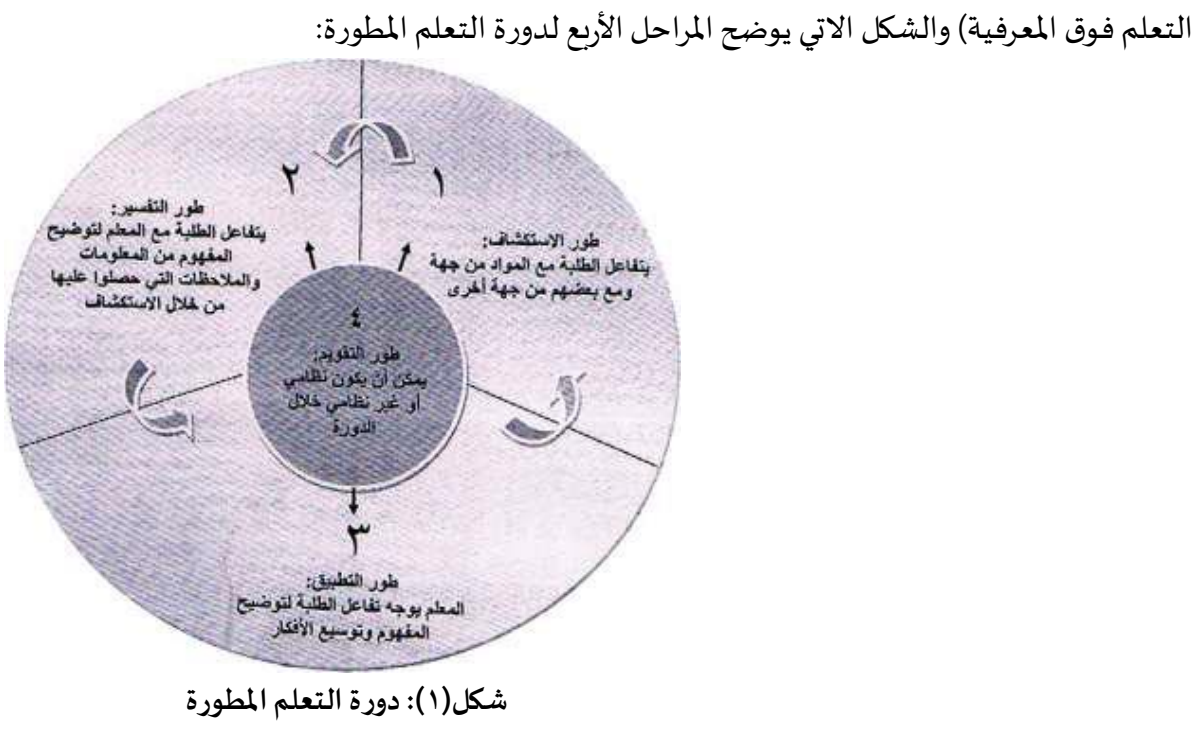

(Barman \& et-al.p :21 .1992)

ولقد اقترح بارمان أن دورة التعلم العادية لا تحتوي على أسلوب محدد لإظهار المعرفة السابقة، فأنموذج بارمان لا يختلف عن دورة التعلم

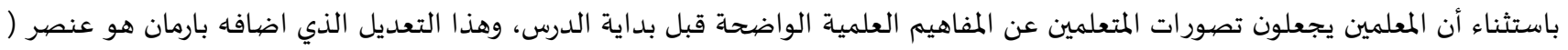


التنبؤ أو التخمين) أو استعمال أوراق التنبؤ للمتعلمين حتى تتضح أفكارهم العلمية، وقد ظهرت دورة التعلم فوق المعرفة بعد دورة بان لتجسيد

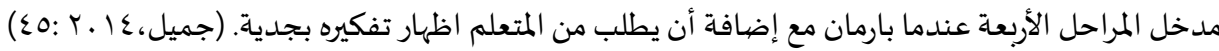
يتكون هذا الأنموذج من أربع مراحل؛ لكنه يختلف عن أنموذج بارمان (Barman, 1989) السابق في تأكيده المعرفة القبلية للطلاب بصفتها

$$
\text { مرحلة تسبق الاستقصياء. }
$$

خطوات التدريس على وفق انموذج بارمان:

ا . مرحلة التحديد أو التخمين (Assessment Phase)؛

يستعمل المدرس أساليب تساعد الطلبة على تحديد معرفتهم عن موضوع الدرس، وهذه التهذه المرحلة تسـاعدهم على التوصل إلى الفهم الصحيح

لمفاهيم الدرس.

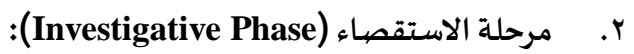

وفيها تقدم مشكلة مفتوحة للطلبة، تتضمن الاسئهن إمكانات واستراتيجيات متعددة لحلها، وهي تهيئ المجال لأنشطة الطلبة، ولأسئلتهم ذات الصلة

بموضوع الدرس.

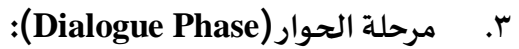

تصبح الخبرة الاستقصائية في المرحلة السابقة الأساس لوضع صياغة علمية للمفهوم.

ع. مرحلة التطبيق (Application Phase):

يتنافس الطلبة لتقديم أمثلة متعددة عن المفهوم، وتطبيق المعلومات التي حصلوا عليها في المراحل السابقة، وعلى الانتقال المعرفي لمهمة

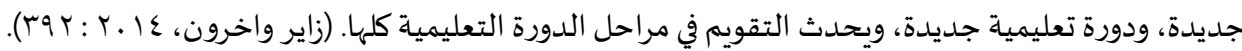

التفكير عالي الرتبة

•

يرى بعض العلماء ان التفكير عالي الرتبة احد أشكال التفكير المتطور كالتفكير الناقد والإبداعي والتفكير ما وراء المعرفة، في حين يرى البعض

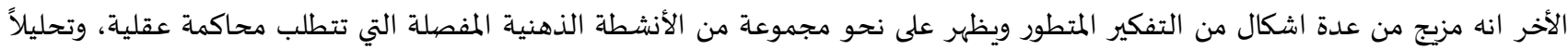

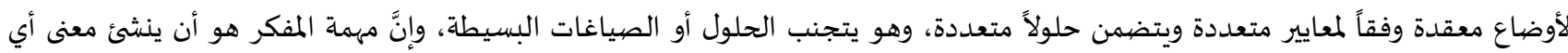

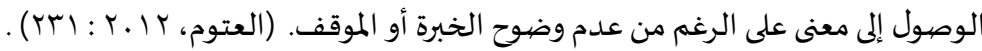

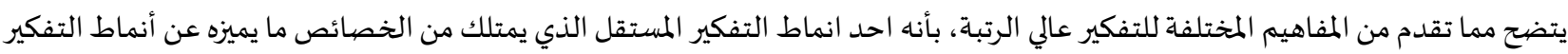
العادي والناقد والابداعي والتأملي وغيرها. كما ركزت غالبية مفاهيم التفكير عالي الرتباة على ثلاثة افتراضات عن التفكير والتعلم هي :

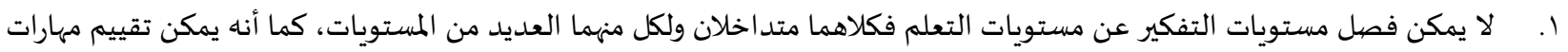

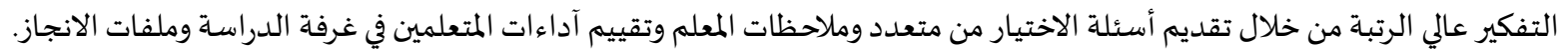
r. أن تعلم مهارات التفكير عالي الرتبة تتضمن العديد من عمليات التفكير التي يمكن تطبيقها في المواقف المعقدة التي تتضمن العديد من المتغيرات. r. من الصعب تعلم مهارات التفكير عالي الرتبة دون وجود مادة للمحتوى، إذ يتعلم الطلاب من الحياة اليومية ومن خبرات غرفة الدراسة

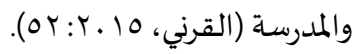
نماذج تصنيف مهارات التفكيرعالي الرتبة هناك العديد من النماذج التي قدمت تصنيفات لمهارات التفكير عالي الرتبة، وكما يأتي:

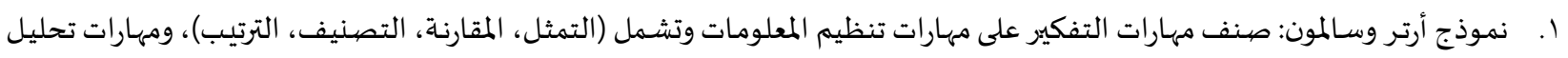

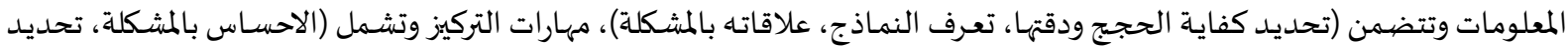

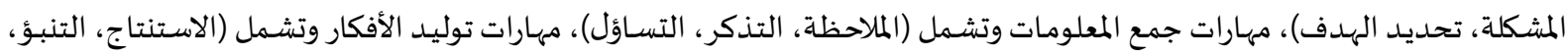
اعادة البناء)، مهارات التركيب وتتضمن (التلخيص، التكامل، تطوير المخرجات)، مهارة التقويم وتشمل (تحديد المعايير الهامة لاصدار المهار حكم ، 
يمثل تصـنيف كارولينـا الشـمالية لمهارات التفكير عـالي الرتبـة الـذي اعـده قسم التعليم العـام لولايـة كارولينـا الشـمالية عـام ع99 الشسخة

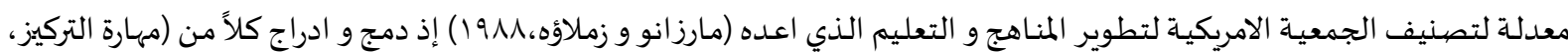

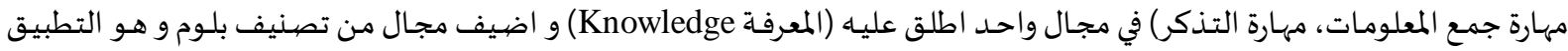
و هو المجـال الذي أهمله مـارزانو و زملاؤه في تصنيف الجمعيـة الامريكية لتطوير المناهج و التعليم ، إذ ان تصينيف كارولينـا

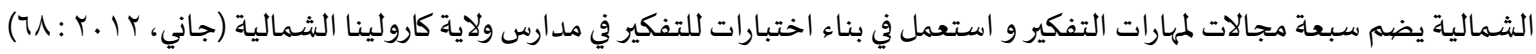

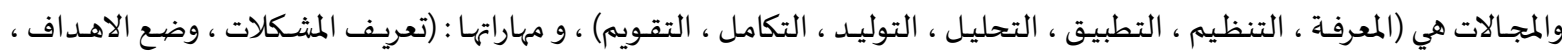

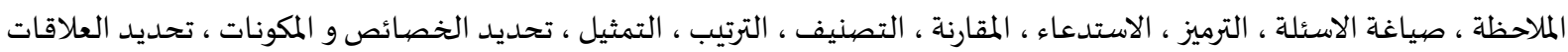

و الانماط ، الاستنتاج ، التنبؤ ، التوسع ، التلخيص ، اعادة البناء ، وضع المعايير و التحقق).

دراسات تناولت انموذج بارمان:

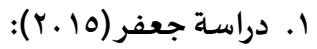

" أثر أنموذجي لورسباش وبارمان في اكتساب المفاهيم البلاغية والأداء التعبيري عند طلبة الصف الخامس الادبي". اجريت هذه الدراسة في العراق/جامعة بغداد/ كلية التربية ابن رشد للعلوم الإنسانياة.

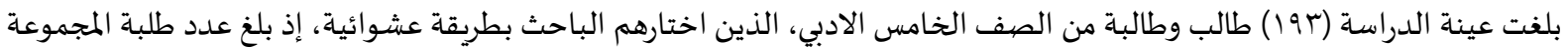
التجريبية الاولى (عا7) طالبا وطالبة، وعدد طلبة المجموعة التجريبية الثانية (70) طالبا وطالبة ايضا، في حين بلغ عدد طلبة المجموعة الضابطة (عابل)

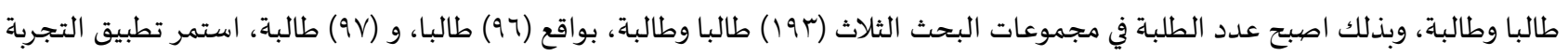

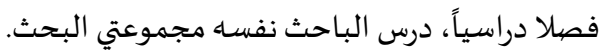

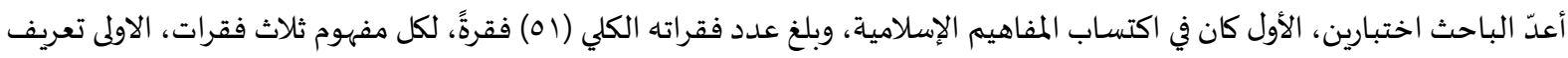

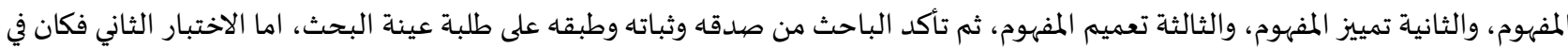
الأداء التعبيري من طريق تحديد موضوع يكتب فياء الطلبة، ثم تصحيحاء وفق محكات التصحيح المتعارف عليها.

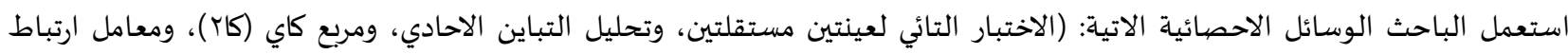

توصلت الدراسة الى ما يأتي:

تفوق طلبة المجموعة التجرببة الأولى الذين درسوا على وفق انموج بارمان على طلبة المجموعة الضابطة الذين درسوا على وفق الطريقة

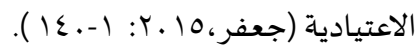

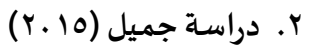

" أثر انموذج بارمان في تنمية الفهم القرائي لدى طالبات الصف الرابع الادبي في مادة المطالعة". اجريت هذه الدراسة في العراق/جامعة ديالى/ كلية التربية للعلوم الانسانية.

بلغت عينة الدراسة (.0) طالبة من طالبات الصف الرابع الادبي في الاعدادية العراقية للبنات في قضياء الخالص، وزعت عشوائياً بين مجموعتين، وبواقع (ro) طالبة في المجموعة التجريبية التي تدرس طالباتها على وفق انموذج بارمان، و(Y0) طالبة في المجموعاة الضابطة التي تدرس طالباتها بالطريقة الاعتيادية، استمر تطبيق التجربة فصلان دراسياً ، درست الباحثة نفسها مجموعتي البحث.

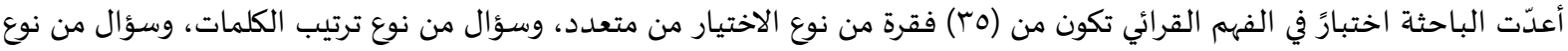

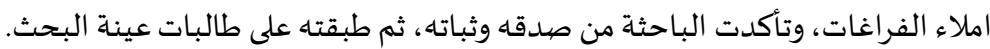

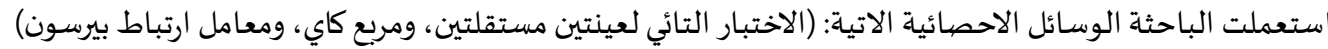

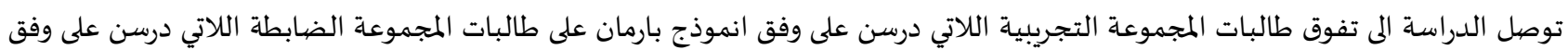

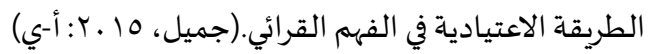

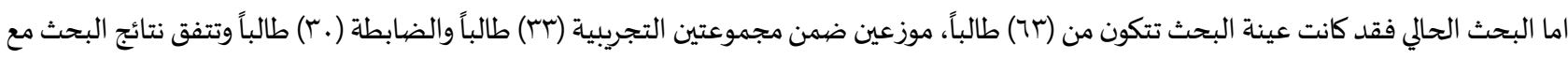
نتائج الدراسات السابقة بتفوق المجموعة التجريبية على المجموعة الضابطة. دراسات تناولت التفكير عالي الرتبة:

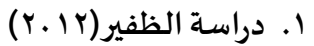


" أثر نموذجي مارزانو وكلوزماير في اكتساب مفاهيم الحديث النبوي الشريف وتنمية مهارات التفكير عالي الرتبة لدى طلبة المرحلة الثانوية

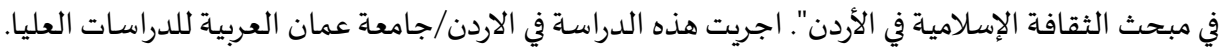

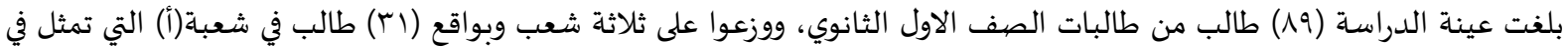

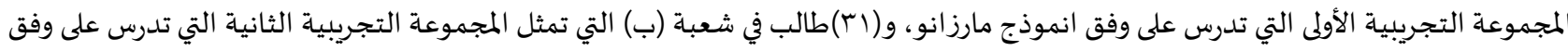

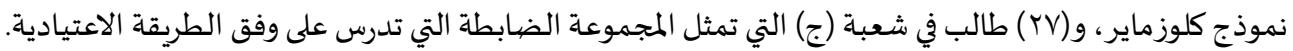

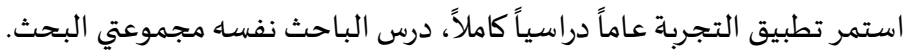

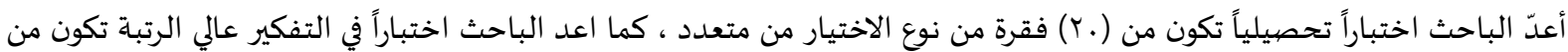

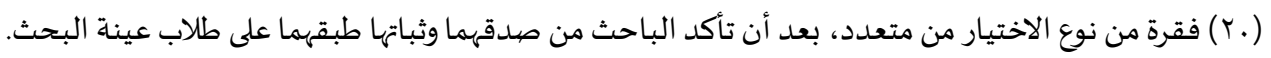

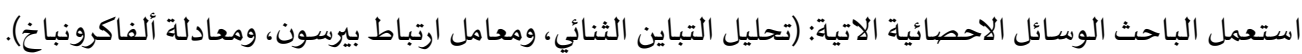
توصلت الدراسة الى ما يأتي: • •فوق الطلاب الذين درسوا على وفق انموذج مارزانو على الطلاب الذين درسوا على وفق الطريقة الاعتيادية في اختبار التفكير عالي الرتبة.

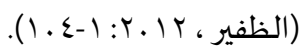

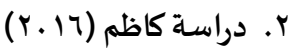
" اثر استراتيجية ثنائية التحليل والتركيب في تحصيل طالبات الصف الرابع العلمي والتفكير عالي الرتبة في مادة علم الأحياء"، اجريت هذه الدراسة في العراق/ جامعة بغداد/ كلية التربية للعلوم الصرفة.

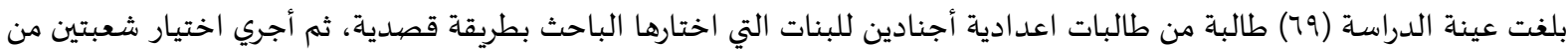

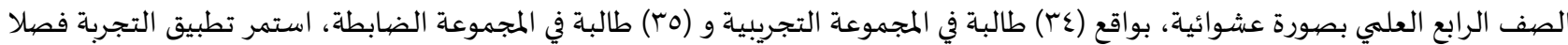

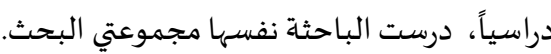

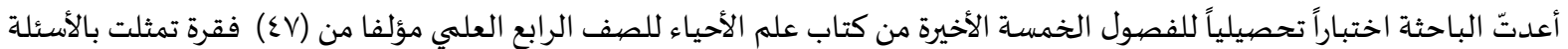

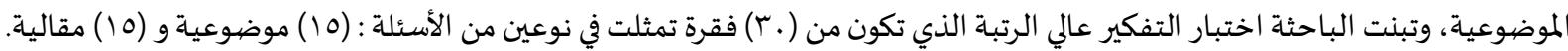

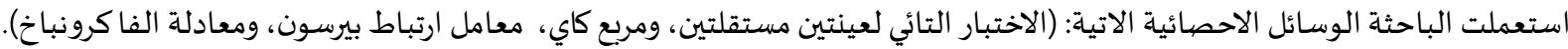
توصلت الدراسة الى :

•وجود فرق ذات دلالة احصائية لصالح المجموعة التجريبية في اختبار التفكير عالي الرتبة وبحجم أثر متوسط للمتغير المستقل بلغ (V,..).

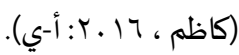

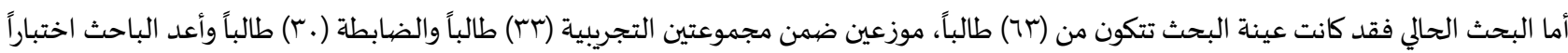
للتفكير عالي الرتبة تكون من (.ع) فقرة، وتتفق نتائج البحث مع نتائج الدراسات السابقة بتفوق المجموعة التجريبية على المجموعة الضابطة في اختبار التفكير عالي الرتبة.

\section{مؤشرات ودلالات من الدراسـات السابقة}

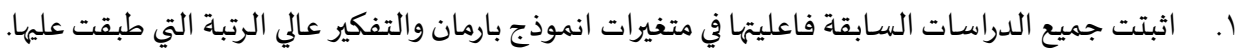

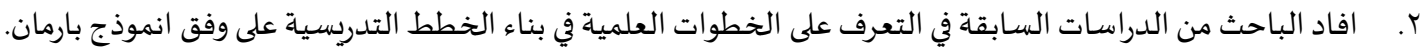
r. افاد الباحث من الدراسات السابقة في التعرف على كيفية اعداد اختبار التفكير عالي الرتبة.

منهجية البحث:

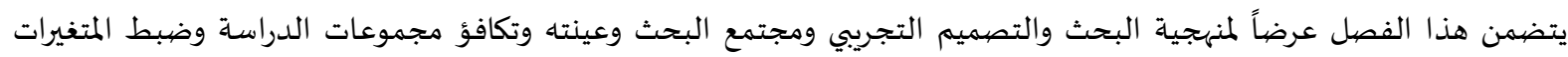

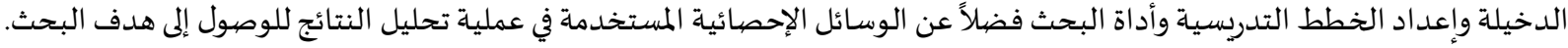

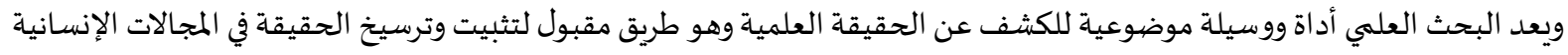

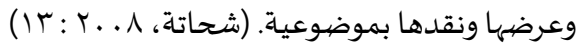
إجراءات البحث:

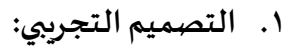


وقد استعمل الباحث التصميم التجريبي ذا الضبط الجزئي، وتصميم المجموعات التجريبية والمجموعة الضيابطة عشوائية الاختيار، ذو

الاختبار القبلي والبعدي، وحسب المتغيرات التي وردت في العنوان وكما موضح في الجدول (1).

جدول (1): التصيميم التجريبي للبحث

\begin{tabular}{|c|c|c|c|c|}
\hline البعدي & المتغير التابع & المتغير المستقل & القبلي & المجموعة \\
\hline \multirow{2}{*}{ اختبار التفكيرعالي الرتبة } & \multirow{2}{*}{ التفكير عالي الرتبة } & انموذج بارمان & \multirow{2}{*}{ اختبار التفكيرعالي الرتبة } & التجريبية \\
\hline & & الطريقة الاعتيادية & & الضابطة \\
\hline
\end{tabular}

r . مجتمع البحث وعينته:

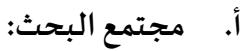

وبما أن البحث الحالي يهدف إلى التعرف على " أثثر أنموذج بارمان في تنمية التفكير عالي الرتبة لدى طلاب الصف الخامس الإعدادي في مادة

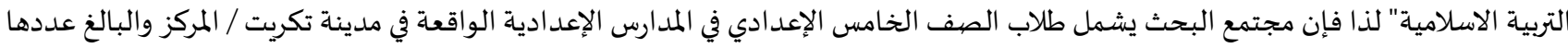

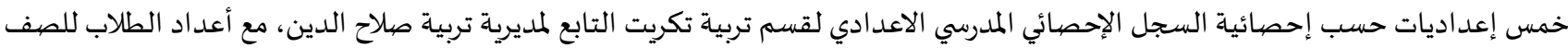

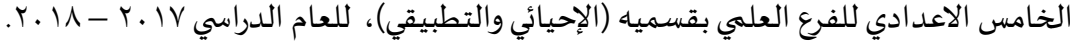

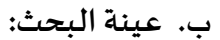

$$
\text { ويمكن تقسيم عينة البحث إلى: }
$$

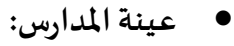

اختار الباحث (إعدادية ابن المعتم للبنين) بصورة قصدية عينة للبحث من بين مدارس البنين الثانوية التابعة للمديرية العامة لتربية صلاح الدين؛ لتكون مجالاً لتطبيق التجربة وذلك. • ع عينة الطلاب:

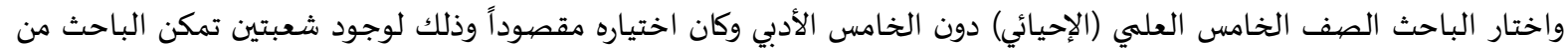

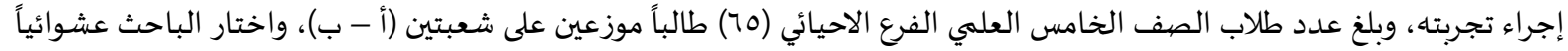

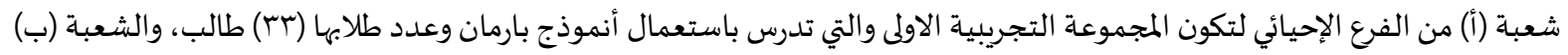

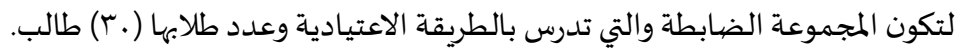

لغرض تحقيق التجانس بين أفراد عينة البحث قام الباحث قبل الشروع بالتجربة بإجراء تكافؤ إحصائي لبعض المتغيرات التي يرى إهها قد تؤثر

$$
\text { في نتائج البحث بين مجموعتي البحث وهذه المتغيرات هي: }
$$

متغير الذكاء: حيث كافئ الباحث بين مجموعتي البحث باستعمال اعتمد الباحث اختبار اوتس (Otis) المصمم لقياس القابلية العقلية

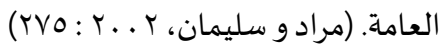

$$
\text { • العمر الزمني للطلاب محسوباً بالأشهر. }
$$

درجات الاختبار الهائي للعام السابق (الرابع الإعدادي) في مادة التربية الإسلامية.

$$
\text { التحصيل التحيل الدراسي للآباء. }
$$

درجات الاختبار القبلي للتفكير عالي الرتباة.

وقد اظهرت النتائج عدم وجود فرق ذو دلالة احصائية في مجال التكافؤ.

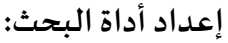

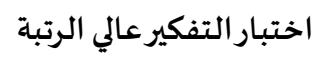

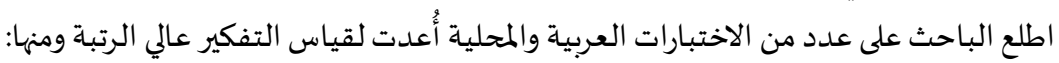

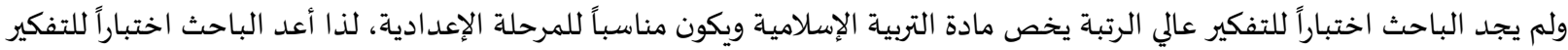

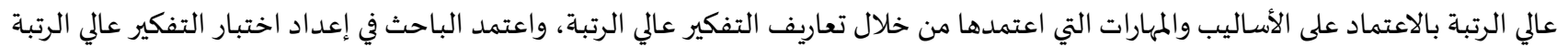


على تصنيف نورث كارولينا الذي أعده قسم التعليم العام لولاية كارولينا الشمالية عام(ع991)، وهو نسخة معدلة لتصنيف الجمعية الامريكية

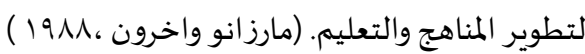
وأعد الباحث اختبارا لقياس التفكير عالي الرتبة يتضمن أربعة مجالات رئيسة هي: (التحليل - التوليد - التكامل - التقويم) وتسع مهارات فرعية هي:

(تحديد الخصائص - المكونات - تحديد العلاقات - الانماط - الاستنتاج - التنبؤ - التوسع - التلخيص - اعادة بناء - وضع الميات المعايير - التحقق) وهي:

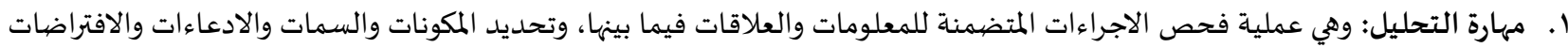

وتمييزها، وتتكون من مهارتين فرعيتين هما (تحديد الخصائص والمكونات - تحديد العلاقات والأنماطي).

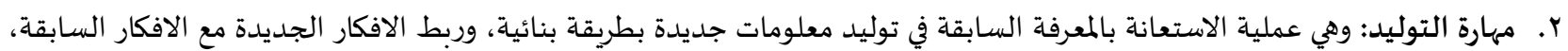

$$
\text { وتتكون من ثلاث مهارات فرعية هي (الاستنتاج - التنبؤ - التوسع). }
$$

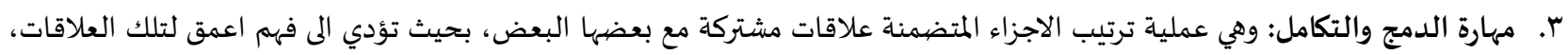
وتتكون من مهارتين فرعيتين هما (التلخيص - إعادة البناء).

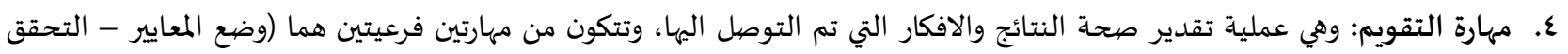
والثبات).

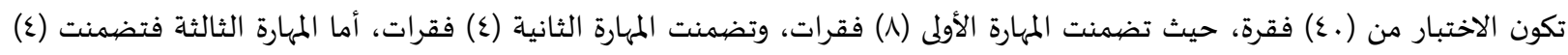

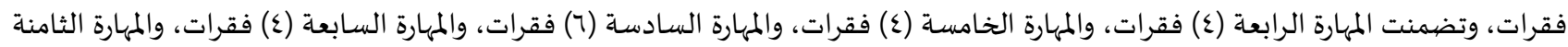

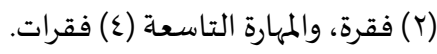
صبدق الاختبار:

اعتمد الباحث في دراسته على الصدق الظاهري في إيجاد صدق أداة البحث، وهو المظهر العام للاختبار من حيث نوع المفردات وكيفية

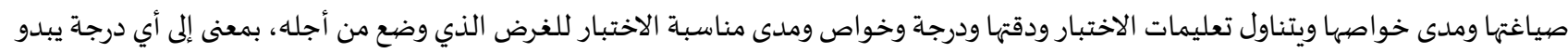

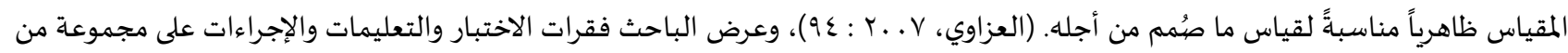

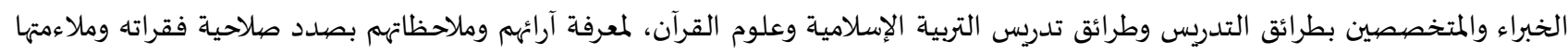

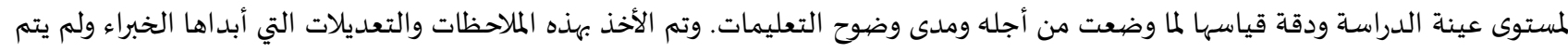

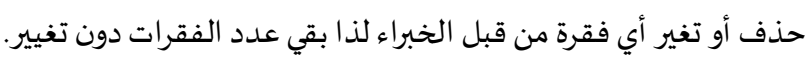

ثبات الاختبار:

وللتحقق من ثبات الاختبار استعمل الباحث طريقة تحليل التباين باستخدام معادلة (الفا - كرونباخ Alfa - Cronbach) لاستخراج

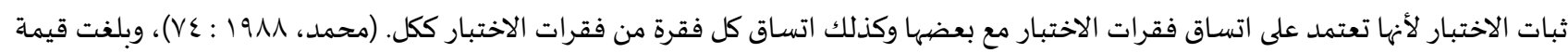

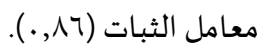
ويشير (1997) (Anastasia \& Urbina) إن اقتراب معامل الثبات من الواحد الصحيح يزيد من الاتساق الداخلي للمقياس. نقلاً عن (الشامي،

$(117: r \cdot 14$

صياغة تعليمات الاختبار:

أ- تعليمات الإجابة: حدد الباحث عدليمات الاخد من التعليمات الخاصة بالاختبار تضمنت قراءة الاختبار بدقة والتأني بالإجابة وعدم ترك اي فقرة بدون اجابة مع تحديد الوقت المخصص للإجابة.

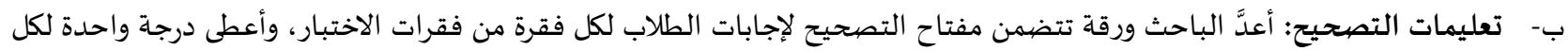

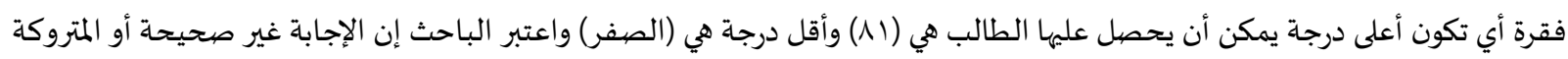

$$
\text { تعتبر الدرجة (صفر). }
$$

العينة الاستطلاعية:

اختار الباحث ( . . 1) طالب من طلاب الصف الخامس الإعدادي في إعداديات مدينة تكريت لإجراء اختبار العينة الاستطلاعية علهيم

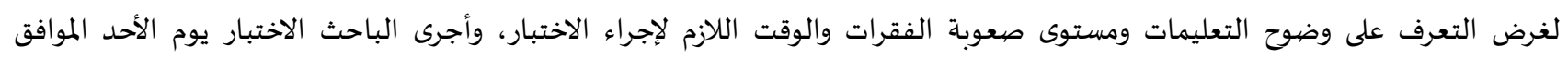

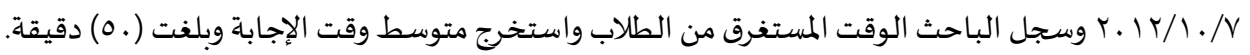


إجراءات تطبيق التجربة:

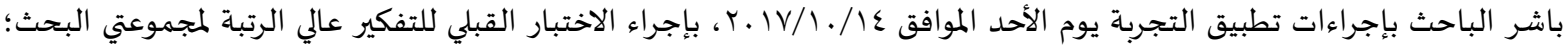

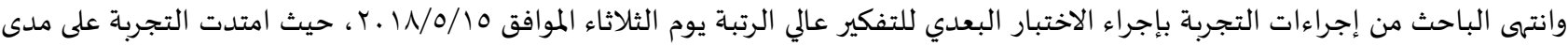
(Tr) أسبوعاً والتي تمثل العام الدراسي. وتولى الباحث تدريس المجموعتين وبواقع حصة واحدة أسبوعياً لكل مجموعة وحسب توزيع مديرية تربية صلاح الدين للحصص الدراسية.

الوسائل الاحصيائية: أ. معامل ألفا كرونباخ : لإيجاد ثبات الاختبارات استعمل الباحث:

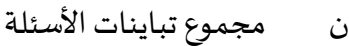

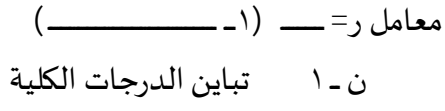

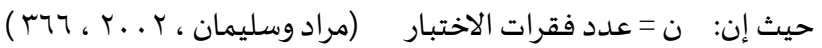
ب. مربع كا' : لإيجاد التكافؤ في التحصيل الدراسي للأبوين.

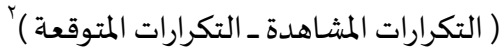

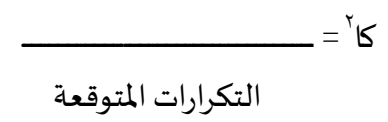

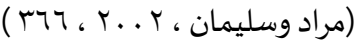

سו - سי ج. الاختبار التائي (t-test) لعينتين مستقلتين :

$\frac{\overline{(r / 1+i(1))^{r} \varepsilon(1-r)+r^{r} \varepsilon(1-i)}}{r-r+i \dot{u}}$

$$
\begin{aligned}
& \text { حيث أن: } \\
& \text { س = الوسط الحسابي للعينة الأولى س = الوسط الحسابي للعينة الثانية } \\
& \text { نr = عدد أفراد العينة الثانية }
\end{aligned}
$$

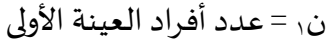

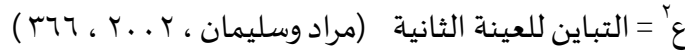

$$
\begin{aligned}
& \text { عُ = التباين للعينة الأولى }
\end{aligned}
$$

\section{عرض النتائج ومناقشتها}

"لا يوجد فرق ذو دلالة احصائية عند مستوى (0. ..) بين متوسط درجات طلاب المجموعة التجريبية الاولى الذين يدرسون باستعمال انموذج

بارمان ومتوسط درجات طلاب المجموعة الضيابطة الذين يدرسون باستعمال الطريقة الاعتيادية في الاختبار البعدي للتفكير عالي الرتبة" وللتثبت من هذه الفرضية الصفرية وتعرف دلالة الفرق بين درجات الاختبار البعدي للتفكير عالي الرتبة للمجموعة (التجريبيةا ـ الضابطة)

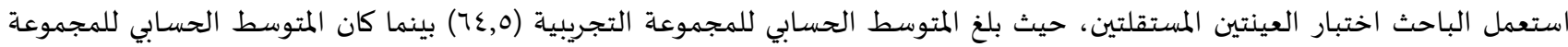
الضيابطة (0乏) وأظهرت النتائج تفوق المجموعة التجريبية على المجموعة الضابطة حيث بلغت القيمة المحسوبة (V,YV) وهي اعلى من القيمة الجدولية البالغة (ع . r) وبذلك ترفض الفرضية الصفرية لتفوق المجموعة التجريبية على المجموعة الضابطة في الاختبار البعدي للتفكير عالي الرتبة، والجدول

\begin{tabular}{|c|c|c|c|c|c|c|}
\hline \multirow{2}{*}{ عند مستوى ه. الدلالة الإحصائية } & \multicolumn{2}{|c|}{ القيمة التائية } & \multirow[t]{2}{*}{ الانحراف المعياري } & \multirow{2}{*}{ الحسابي } & \multirow[t]{2}{*}{ العدد } & \multirow[t]{2}{*}{ المجموعة } \\
\hline & الجدولية & المحسوبة & & & & \\
\hline \multirow[t]{2}{*}{ دالة إحصائيا } & \multirow[t]{2}{*}{$r, . \varepsilon$} & \multirow[t]{2}{*}{$V, r V$} & 9,00 & $I \leqslant, 0$ & $r \mu$ & التجريبية \\
\hline & & & $\{, \Lambda \uparrow$ & £o & $r$. & الضيابطة \\
\hline
\end{tabular}
(r) يوضح النتائج.

جدول (Y) : نتائج الاختبار البعدي للتفكيرعالي الرتبة 
الاستنتاجات:

في ضوء النتائج التي ظهرت في الدراسة الحالية قدم الباحث عدداً من الاستنتاجات وهي:

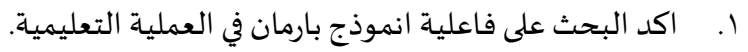

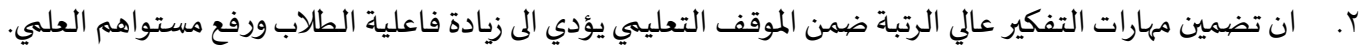
r. أسهم أنموذج بارمان في تنمية القدرات العقلية لدى الطلاب من خلال خطواته التي حققت نتائج افضل في اختبار التفكير عالي الرتبة.

التوصيات:

في ضوء نتائج البحث وضع الباحث عدداً من التوصيات آملاً الاخذ بها من ذوي الشأن:

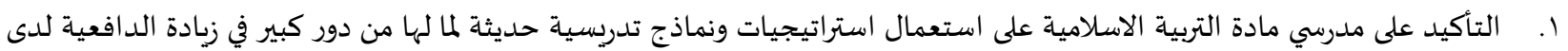
الطلاب ورفع مستويات التفكير. r. إقامة عدد من الدورات والندوات التي تستهدف مدرسيً مادة التربية الاسلامية للتعريف بالتفكير عالي الرتبة ومهاراته وكيفية الاستفادة منه في الموقف التعليهي. r. حث المدرسين على ضرورة استعمال المستويات الثلاث العليا من مستويات الاهداف وعدم التركيز على الحفظ والاستظهار فقط. المقترحات:

اقترح الباحث عدداً من الاقتراحات لاستكمال دراسته الحالية وهي: ا. إجراء دراسة مماثلة للدراسة الحالية وعلى مراحل دراسية مختلفة ومواد دراسية اخرى.

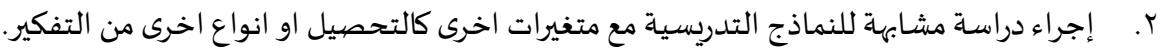
r. استعمال نماذج دراسية اخرى من ضمن نماذج النظرية البنائية مع متغير التفكير عالي الرتبة.

ا. آدي، فيليب وميخائيل شاير، (و . . ب) التدخل المعرفيّ والتحصيل الأكاديميّ ورفع المعايير التربوية، ترجمة زبنات دعنا. عمان، دار الفكر. r. جاني، نوال جوحي، ( ا ـ †) فاعلية برنامج تدريبي قائم على عادات العقل في تنمية مهارات التفكير عالي الرتبة عند طلبة المرحلة الاعدادية.

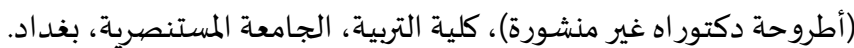

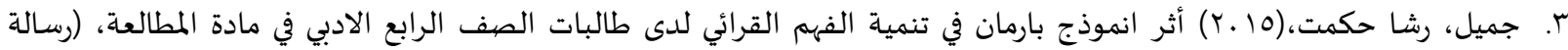
ماجستير غير منشورة)، جامعة ديالى، كلية التربية للعلوم الإنسانية.

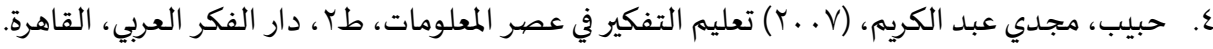

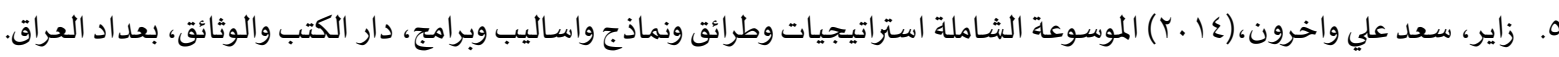

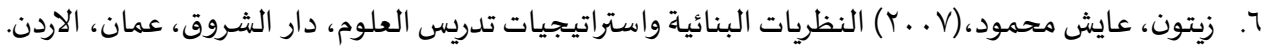

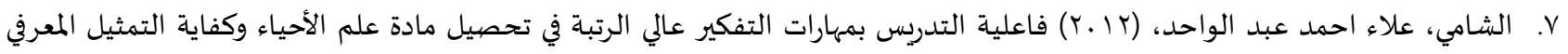

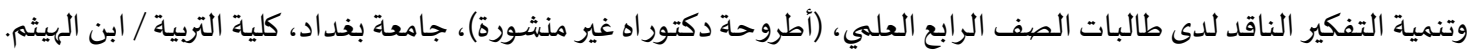

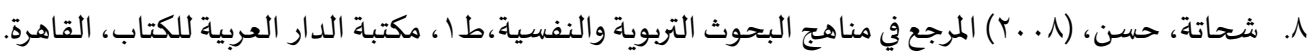

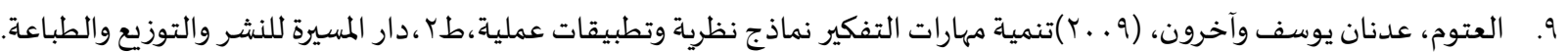

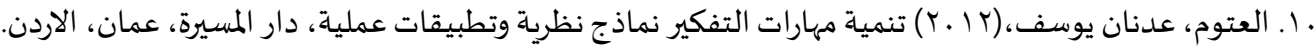

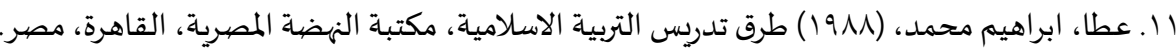

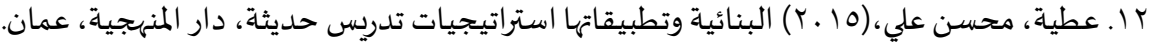

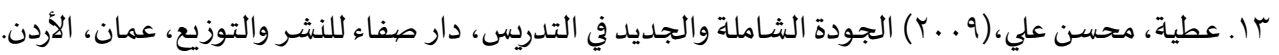

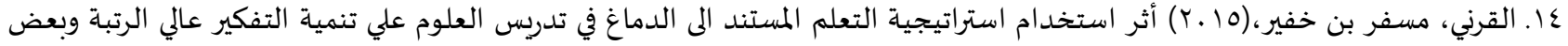
عادات العقل لدى طلاب الصف الثاني المتوسط ذوي انماط السيطرة الدماغية المختلفة، (اطروحة دكتوراه غير منشورة)، كلية التربية الاساسياة، جامعة ام القرى، المملكة العربية السعودية. 
0 ا. كاظم، رباب عبد الواحد، (Y ا ـ) فاعلية برنامج مقترح على وفق نظرية الذكاءات المتعددة في تنمية مهارات القراءة الناقدة والكتابة الإبداعية

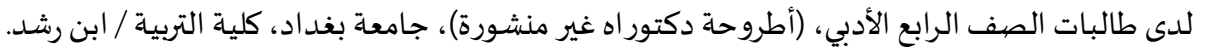

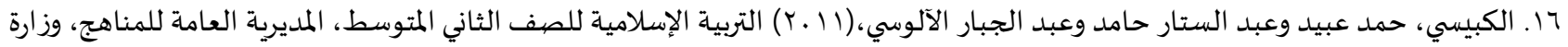

$$
\text { التربية، العراق. }
$$

V V ا اللولو، فتحية، واحسان الاغا،(V . . †) تدريس العلوم، كلية التربية، الجامعة الإسلامية، فلسطين.

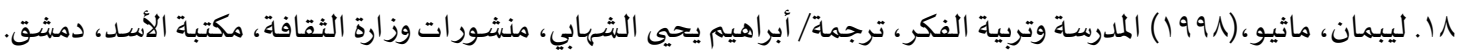

19 ا. محمد، محمد سيد، الإعلاموالتربية، دار الفكر العربي، القاهرة.

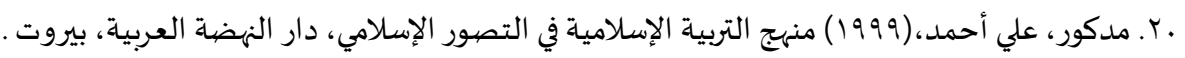

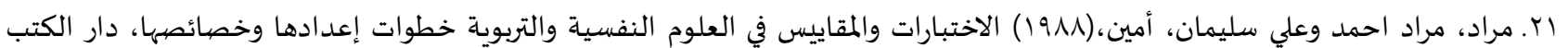

$$
\text { الحديث، القاهرة. }
$$

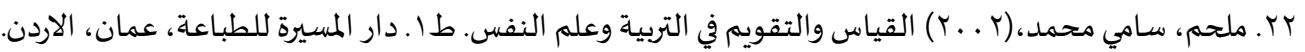

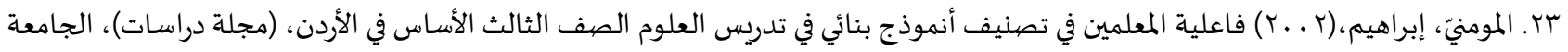

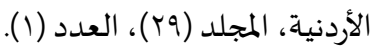

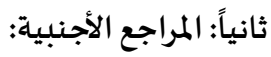

[1] Barman. R. C, cohen, Bridging the Gap between the old and the new, (2004). 


\title{
The Impact of the Barman Model in the Development of High-Grade Thinking among Students in the Fifth Grade Preparatory in Islamic Education in the State of Iraq
}

\author{
P. Dr. Raed Idris Mahmoud \\ University of Tikrit Girls College of Education- University of Tikrit
}

Ihsan Nadher Hussein

College of Education for Humanities

\begin{abstract}
:
The current research aims to identify the "impact of the Barman model in high-level thinking among fifth grade students in Islamic education in the State of Iraq"

The researcher formulated the following zero hypothesis:

"There is no statistically significant difference at $(0.05)$ between the mean scores of the experimental group using the Barman model and the mean scores of the control group students who are studying using the standard method of post-high-level thinking"

In order to achieve the research objective, the researcher followed the experimental method. He chose the experimental design with partial control of the experimental and control groups. His choice was intentional, because the experimental approach is the closest method of research to solve the problems in the scientific way, and the most suitable approach to solving the educational problems and developing the education structure and its different systems. (Melhem, 2002: 388)

The research society consists of the students of the fifth grade preparatory / scientific branch in the city of Tikrit center (Iraq), which number (414) students, which equivalent to stage (11) in a number of Arab countries, and chose one of the morning economics of the Department of Education Salah Eddin / Department of Education Tikrit, Ibn al-Mu'tam for boys located in Tikrit Al-Qadisiyah neighborhood.

The research society consists of the students of the fifth grade preparatory / scientific branch in the city of Tikrit center (Iraq), which number (414) students, which equivalent to stage (11) in a number of Arab countries, and chose one of the morning economics of the Department of Education Salah Eddin / Department of Education Tikrit, Ibn al-Mu'tam for boys located in Tikrit Al-Qadisiyah neighborhood.

The number of students in the research sample was 63 students, distributed in two groups to be one of them experimental and the number of students was 33 students, the other was an officer and the number of students was 30 students., The tribal test of high-level thinking), and the results showed that the experimental group exceeded the control group in the post-test of high-level thinking,The researcher presented a number of conclusions, recommendations and proposals:
\end{abstract}

Keywords: Barman model, high-level thinking

\section{References:}

[1] 'țạ. Ạbrạhym Mḥmd, Ṭrq Tdrys Ạltrbyh Ạlạslạmyh, Mktbë Ạlnhụh Ạ̣lmṣryh, Ạlqạhrh, Mṣr, (1988).

[2] 'țyh. Mḥsn 'ly, Ạlbnậyh Wtṭbyqạthạ Ạstrạtyjyạt Tdrys Ḥdytḥt, Dạr Ạlmnhjyh, 'mạn, (2015).

[3] 'țhh. Mḥsn 'ly, Ạljwdh Ạlsḥạmlh Wạljdyd Fy Ạltdrys, Dạr Șfạa' Llnshِr Wạltwzy', 'mạn, Ạlạ̉rdn, (2009).

[4] Ậdy. Fylyb Wmykhạảyl Shạyr, Ạltdkhַl Ạlm rfỹ Wạltḥsyl Ạlạ̉kạdymỹ Wrf' Ạlm ạyyr Ạltrbwyh, Trjmë Zynạt D'nạ. 'mạn, Dạr Ạlfkr, (2009). 
[5] Ạl twm. 'dnạn Ywsf, Tnmÿ̈ Mhạrạt Ạlttkyr Nmạdḥj Nẓrÿ̈ Wtṭbyqạt 'mlyh, Dạr Ạlmsyrh, 'mạn, Ạlạrdn, (2012).

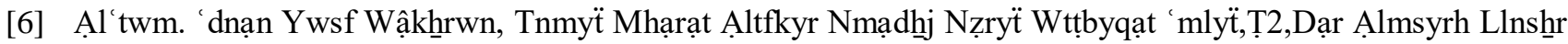
Wạltwzy' Wạlțbạ ho, (2009).

[7] Ạlkbysy. Ḥmd 'byd , 'bd Ạlstạr Hạmd \& 'bd Ạljbạr Ạlậlwsy, Ạltrbyh Ạlạslạmyh Llṣf Ạlthạany Ạlmtwsṭ, Ạlmdyryh Ạl'ạmh Llmnạhj, Wzạrẗ Ạltrbyh, Ạl'rạq, (2011).

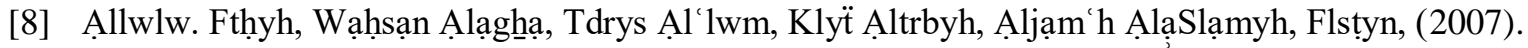

[9] Ạlmwmnỹ. Abrạhym, Fạ lyë Ạlm lmyn Fy Tṣnyf Ạ̉nmwdhnj Bnạỷy Fy Tdrys Ạl'lwm Ạlṣf Ạlthạaltḥ Ạlạ̉sạs Fy Ạlạ̉rdn, (Mjlt Drạsạt), Aljạ̣m h Ạlạ̉rdnyh, 29(1)(2002).

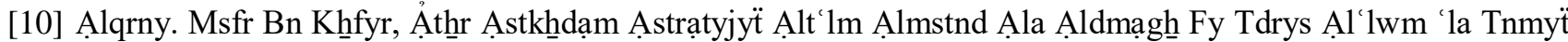

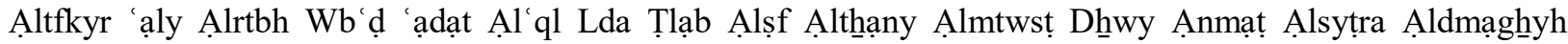

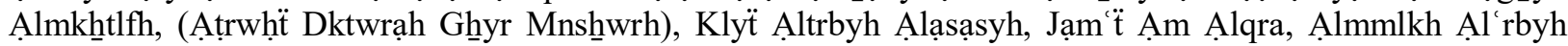
Als'wdyh, (2015).

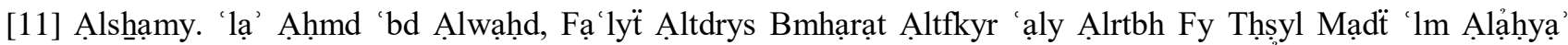
Wkfạyt Ạltmthyl Ạlm rfy Wtnmÿ̈ Ạltfkyr Ạlnạqd Lda Tạlbạt Ạlș̣ Ạlrạb Ạl lmy, (Ậțrwḥ̂t Dktwrạh Ghyr

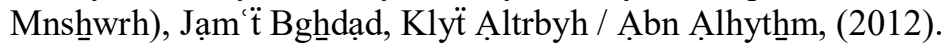

[12] Ḥbyb. Mjdy ‘bd Ạlkrym, T’lym Ạltfkyr Fy 'ṣr Ạlm lwmạt, Ṭ2, Dạr Ạlfkr Ạl'rby, Ạlqạhrh, (2007).

[13] Jạny. Nwạl Jwhy, Fạ lyë Brnạmj Tdryby Qạymm 'la 'ạdạt All'ql Fy Tnmÿ̈ Mhạrạt Ạltfkyr ‘ạly Ạlrtbh 'nd Ṭlbë

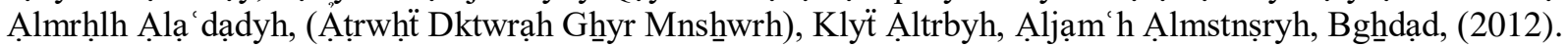

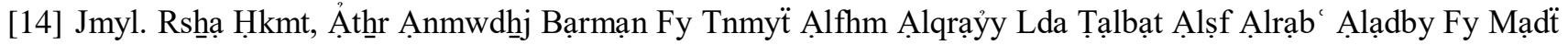
Ạlmțạl'h, (Rsạlẗ Mạjstyr Ghyr Mnshwwrh), Jạm ‘̈ Dyạla, Klÿ̈ Ạltrbyh Ll'lwm Ạlạinsạnyh, (2015).

[15] Kạzm. Rbạb 'bd Ạlwạhd, Fạ 'lÿ̈ Brnạmj Mqtrḥ 'la Wfq Nzryë Ạldhnkạa ạt Ạlmt ddh Fy Tnmyë Mhạrạt Ạlqrạ h

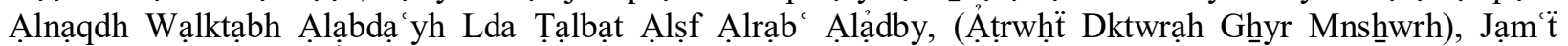
Bghạdạd, Klyë Ạltrbyh / Ạbn Rsho, (2012).

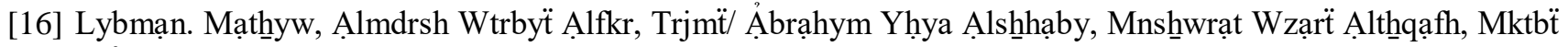
Ạlạ̉sd, Dmsh̆q, (1998).

[17] Mdkwr. 'ly Ạ̉ḥmd, Mnhj Ạltrbyh Ạlạslạmyh Fy Ạltṣwr Ạlạslạmy, Dạr Ạlnhḍh Ạl rbyh, Byrwt, (1999).

[18] Mḥmd. Mḥmd Syd, Ạlạ 'lạm Wạltrbyh, Dạr Ạlfkr Ạl'rby, Ạlqạhrh.

[19] Mlḥm. Sạmy Mḥmd, Ạlqyạs Wạltqwym Fy Ạltrbyh W'lm Ạlnfs, Ṭ1, Dạr Ạlmsyrh Llṭbạ ho, 'mạn, Ạlạrdn, (2002)

[20] Mrạd. Mrạd Ạhmd \& 'ly Slymạn. Ảmyn, Alạkhḥtbạạat Wạlmqạyys Fy Ạl'lwm Ạlnfsyh Wạltrbwyh Kḥtwạt Ạ̛ dạdhạ Wkḥsạỷṣhạ, Dạr Ạlktb Ạlḥdytḥ, Ạlqạhrh, (1988)

[21] Sḥhạth. Ḥsn, Ạlmrj‘ Fy Mnạhj Ạlbḥwthِ Ạltrbwyh Wạlnfsyh,Ṭ1, Mktbë Ạldạr Ạl'rbyh Llktạb, Ạlqạhrh, (2008).

[22] Zạyr. S'd 'ly Wạkḥrwn, Ạlmwsw'h Ạlsḥạmlh Ạstrạtyjyạt Wṭậ̉q Wnmạdḥj Wạsạlyb Wbrạmj, Dạr Ạlktb Wạlwthậyq, B' dạd Ạl rạq, (2014).

[23] Zytwn. 'ạysḥ Mḥmwd, Ạlnzryạt Ạ̣lbnạyyh Wạstrạtyjyạt Tdrys Ạl'lwm, Dạr Ạlsḥrwq, 'mạn, Ạlạrdn, (2007). 